Revista da ANPOLL, n 4, p. 249-261, jan./jun. 1998

\title{
A ESCRITA NA FÁBULA DE ARQUÍLOCO (FR.185)
}

Paula Corrêa*

\begin{abstract}
RESUMO: A "skutále" no fragmento 185W de Arquíloco suscitou, desde a antigüidade, diversas leiluras. Já foi interprelada como sendo uma "mensagem escrita" (cifrada ou não), um "bastão" (que levava de alguma forma a mensagem, ou apenas identificava o mensageiro), e o próprio "mensageiro". Para ler esses versos que introduzem a "Fábula da Raposa e do Símio" (Fr: 1S5-7) e especificar o significado da palavra nesse contexto, analisamos os sentidos de "aînos" (fábula grega), as fontes do fragmento, os testemunhos da "skulále", e outras formas de. despachos na Grécia arcaica.
\end{abstract}

PALAVRAS-CHAVE: escrita; fábula; lírica grega arcaica.

$\$$ abe-se que a escrita havia sido reintroduzida na Grécia no $\checkmark$ oitavo século a. C. e que, em passagem controvertida da Ilíada (6.168), talvez os "sinais lúgubres" aos quais o aedo se refere façam alusão a esses novos sinais gráficos. Desde o período alexandrino, até o moderno, persiste uma discussão sobre a natureza desses sinais: seriam apenas marcas mnemônicas, os sinais do linear B, ou as novas letras do alfabeto recém introduzido? De qualquer forma, pelo menos um século mais tarde, é certo que Arquíloco de Paros, se não a dominava, estaria no mínimo a par desta nova tecnologia. Temos por cvidência a inscrição em alfabeto arcaico da lápide que pertencera a Clauco, filho de Leptines, o companheiro citado pelo menos cinco vezes pelo poeta ${ }^{1}$.

Se Arquíloco sabia escrever e/ou ler, e se teria redigido seus próprios poemas, são questões que dificilmente algum dia seremos capazes de responder. Podemos apenas optar entre hipóteses que nos parecem mais ou menos verossímeis. Dentre essas, dado o estilo dos fragmentos que nos

\footnotetext{
* Universidade de São Paulo - USP.

1 Fr: 15, 48.7, (96), 105.1, 117, 131.1W. Cf. Pouilloux (1955, p.74ss).
} 
CORRÊA, Paula. A escrila na fábula de Arquíloco (Fr.1S5).

restaram, e pelo que sabemos dos poetas inseridos em cultura basicamente oral, como seria a do período arcaico, é provável que a composição dos poemas se desse oralmente, sendo eles transcritos mais tarde por um escriba que os soubesse de cor, ou ao qual os versos foram ditados. Ou, ainda, nada impede que tenham sido registrados, após sua composição, pela mão do próprio pocta².

Possuímos, além da evidência externa da lápide de Glauco, um fragmento de Arquíloco no qual parece haver referência à escrita, isto ć, a um de scus suportes materiais. Esta é, ao menos, a leitura tradicional que se faz da akhnuméne skutále (_cnum_nh skut_lh), presente nos dois primeiros versos que introduzem a Fábula da Raposa e do Símio (Fr: 185-7W). No cntanto, o que a aknuméne skutále significa exatamente, c a que (ou a quem) se refere, tem sido um problema desde o período alexandrino.

Assim, para tratar especificamente da escrita em Arquíloco, c das questões que a skutále envolve, comentaremos o início do fragmento $185 \mathrm{~W}$ :

v.1

$$
\begin{aligned}
& \text { _r_w tin'_min a_non, _ Khruk_dh, } \\
& \text { cnum_n_skut___ } \\
& \text { Contar-vos-ei uma fábula, ó filho do arauto, } \\
& \text { triste mensagem }
\end{aligned}
$$

Os dois versos não apresentam maiores dificuldades - exceto pela própria akhnuméne skutále que será discutida adiante ${ }^{3}$. Quanto aos fragmentos

2 Segundo Barron, J. P. \&. P. E. Easterling (1989, p. 87), "a maioria dos estudiosos acredita que Arquíloco era poeta letrado". Centili $(1988$, p. 20$)$, ao contrário, argumenta a favor de uma composição e transmissão oral dos poemas.

3 Os editores (Lichel 1812; Schneidewin 1838; Bergk 1882, 19152; Hiller 1890; Hoffmann 1898; Dichl 1926; Edmonds 1931; Treu 1959; Tarditi 1968; Lasserre-Bonnard 1968) trazem _ $\mu_{-} \nu$ c não_ $\mu$ เv,

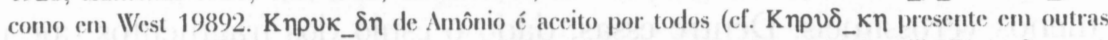
fontes); $c$ o único adotar_ $\chi v v \mu_{-} v_{-} \sigma \kappa v \tau_{-} \lambda_{-}$do texto de Epimer: in Hom. (An Par. iii.371.1+ Cramer) c. Apostólio (pracl. Paroem. Cr: ii.236.6) foi West. Os demais optaram pelo nominativo presente em todas outras fontes. Page $(196+, p .1+1)$ deixa _ $\chi v v \mu_{-} v \eta \sigma \kappa v \tau \_\lambda \eta$ no nominativo, porém, entre cruzes, afirmando não saber do que se trata. 
Revista da ANPOLL, n" 4, p. 249-261, jan./jun. 1998

que pertenceriam ao poema como um todo, c as reconstruções da fábula sugeridas por comentadores e editores, há maiores divergências das quais, agora, não iremos tratar ${ }^{+}$.

\section{A) O AîNOS}

O dístico é citado por Pscudo-Amônio (de adfïn. vocab. diff. 18 (p.5 Nickau), editor bizantino do tratado Sobre vocábulos semelhantes $e$ diversos (per__moi_n ka_diafor_n lex_wn) ${ }^{5}$. Oaînos é aí definido como um discurso mítico de animais e plantas dirigido aos homens, e PseudoAmônio cita, como primeiro exemplo, o fragmento $174 \mathrm{~W}$ de Arquíloco sobre a Fábula da Raposa e da Águia e, logo a seguir, o Fr. $185 \mathrm{~W}$ cm questão ${ }^{6}$.

O que é propriamente o aînos, traduzido aqui por "fábula" que o "eu" do poema contará ao "filho do arauto" (v.1)? O texto de PscudoAmônio (loc. cit.), e as demais fontes que dele dependem (cf. n. 6), o têm como sinônimo de "provérbio", "máxima". Mas, após a citação de um aînos em Hesíodo (Erga 202-3) e em Calímaco (Fr. 194.6-8Pf), respectivamente como exemplos de fábula animal e vegetal, especifica-se o aînos como sendo um "provérbio desenvolvido" que, por meio da narrativa, completa o pensamento para exortar c auxiliar os homens. Portanto, o â̂nos seria uma narrativa com função parenética. Nessa linha, quando Aélio Teão (Progymnasmata 3) define a fábula como "um lógos fictício porém verossímil" (I_goV yeud_V e_kon_zwn __qcian), ele nota que os poetas antigos a chamavam de aînos por ela conter uma admoestação (paraínesis).

4 No entanto, parece indiscutivelmente acertada a hipótese, defendida por todos editores do texto, de que os seis versos do Fr: 185W pertençam, nessa ordem, ao mesmo poema (Cf. contra: I uria, 1930).

5 Esse dicionário de sinônimos, que serviu de fonte para muitos lexicógrafos e comentadores da antigïidade tardia, era obra de I lerênio, gramático e historiador grego de Bíbles (séc. I-ll d. C.).

6 A fonte de Pseudo-Amônio (loc. cit.) é o primeiro livro de provérbios de I ucio de larra (poeta, gramático e retor do séc. I d. C.). Muito semelhantes são os textos presentes nas demais fontes do Fr. 185iV: Epimer: in Ilom., An Par. iii.371.1+ Cramer; Apostol. pracl., Parocm. Gr. ii.236.6; Eust.in Ilom. p.1768.65 ex Eren. Phil.; Et. Gud. i.48.18 de Stephani. 
CORRÊA, Paula. A escrila na fábula de Arquíloco (Fr. / S.5).

Nas ocorrências de aînos em Homero? , trata-se de uma narrativa, um conto, que geralmente traz um recado, uma "mensagem para o ouvinte" (Richardson, 1993, p.240). Mas é possível contar uma cstória, relatar as aventuras de um terceiro, fazendo seu elogio e o tornando célebre como o Odisseu "de muitos aînoi" (pol_ainoV); ou contar uma estória com um propósito moral, de forma mais ou menos explícita (Od. 21.110), em gênero sério ou satírico ${ }^{8}$. De todo modo, aînos é sempre um conto carregado de sentidos e cuja mensagem pode ser enigmática. Assim, aînos se traduz por "fábula" ou "provérbio" quando sua mensagem tem caráter moral; por "enigma" ou "charada" quando ela é obscura, cifrada".

Nota-se logo a distância que existe entre o aînos grego c a fabula latina. Em primeiro lugar, o aînos não parece constituir um "gênero" propriamente dito. Não discutiremos aqui o momento $\mathrm{cm}$ que a fábula teria alcançado este estatuto literário, se foi com Esopo (Lasserre, 1984, p.91), ou apenas com Fedro ou Bábrio (Cf. Easter-ling, 1985, p.702; c Perry, 1965, p.xii). Fato é que, em Arquíloco, Hesíodo, c nos demais poetas gregos, tanto nos arcaicos quanto nos clássicos, o aînos jamais aparece como uma narrativa completa em si, como as fábulas das coleções posteriores. Ele sempre está inserido em um contexto maior. Desta forma, os poemas jamais se iniciam com a simples narração do aînos, mas ele é destacado, isolado, seja por um personagem, seja pelo "eu" lírico que o introduz na apóstrofe, como no dístico inicial deste fragmento $185 \mathrm{~W}$ (veja também Fr. 168, 172W).

O aînos, como dizem os poetas, ou lógos, como começa a ser chamado a partir do séc. V a. C. (provavelmente devido à circulação das fábulas $\mathrm{em}$ prosa atribuídas a Esopo), encontra-se em diversos gêneros literários como um elemento retórico ${ }^{10}$. Aristóteles (Retórica II. 20.1393b22-

7 Cf. Il. 23.652. 795; Od. 14.508.

8. Veja, por exemplo, ćpainos que significa "louvor", e ainíssomai que é "falar obscuramente por meio de cnigmas". Cr. Sólocles, Phil. 1380 (Verdenius, 1962, p.389); Ésquilo, Ag. 1+82ss.; Eurípides, Ion. +30.

9 Ilesíodo, Erga, 202ss; Arquíloco Fr: 172, 185W; Calímaco Fi: 194.6-8 Pf; cf. ISJ.

10 Hesíodo (Erga, 201-12) e Arquíloco (Fr: 17ł, 185W) empregam o termo cînos. Há testemunhos de un "aînos cário" em Timocreonte $(73+P M G)$ e Simônides $(51+P M G)$; mas o que a fonte de Timocreonte 
Revista da ANPOLL, n” 4, p. 249-261, jan./jun. 1998

1394al) classifica estes lógoi como pertencentes ao tipo de "exemplo" em que os eventos narrados são fictícios ${ }^{11}$.

Esse recurso, porém, não parece ter sido empregado indiferentemente em qualquer gênero literário. Lasserre (1984, p.67) nota a ausência de fábulas na poesia épica e nos /linos / Ioméricos. A seu ver, o recorte se deve à incompatibilidade entre o discurso homérico e o fabular, pois "a conduta do animal na fábula não é heróico" (Las-serre, loc. cit.) ${ }^{12}$. Se o recurso à fábula parece restrito a certos gêneros, a causa disso não scria, porém, a apontada por I_asserre, pois há fábulas nas tragédias de Ésquilo, cuja linguagem também pertence ao registro "elevado" e "heróico". Todavia, é interessante notar a semelhança formal dos fragmentos de Arquíloco que contêm fábulas. É possível que fossem originalmente associadas a um sub-gênero como, talvez, ao jambo. Pois todas as fábulas de Arquíloco, pelo menos as que nos restaram, encontram-se em cpodos jâmbicos, assim como as fábulas versificadas por Calímaco.

Quanto à sua função, o aînos, em Arquíloco, é sempre dirigido a uma pessoa/personagem específica, com intenções ao mesmo tempo admoestatórias e satíricas (Hauvette, 1905, p.176). Ao contrário dos aînoi em Homero e Hesíodo, o elemento lúdico sempre está presente, como neste poema ${ }^{13}$.

(730 PMC) chama de "chînos cíprio", o próprio pocta parece chamar de lógos (cl. v.1). Aînos seria a palavra mais antiga e poética que, no entanto, não entra em desuso quando lógos começa a ser empregado no séc. V a. C. Aristólanes, por exemplo, faz uso indiscriminado dos termos: refere-se ora aos lógoi (Pax. 129), ora cî̀noi (Av. 651-3) de Esopo.

11 Segundo Aristóteles (Réórica II.20.139.3122-1394al), entre os tipos de "provas" ( $\pi$ $\sigma \tau \varepsilon ı$ ) comuns a toda retórica, há os exemplos (par_-deigma) e enlimemes ( $v \theta \mu \eta \mu \alpha)$, sendo que os exemplos se dividem entre (1) os que relatam eventos passados, e (2) os que os inventam; este último tipo de exemplo é, por sua vez, subdividido $\mathrm{em}$ comparações (parabolaí) e fúbulas (lógoi). É evidente que estes lógoi são "fábulas" pois,

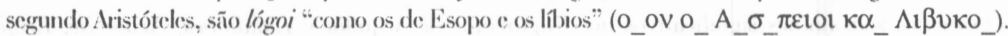

12 No cntanto, Lasserre se contradiz quando afirma em outra passagem (1984, p.80) que a fábula "adota ou reflete a moral aristocrítica". Talvez ele tivesse em mente uma das fontes de 185.2W (Lasserre, 1984, p.67): ao comentar a adequação do ritmo ao conteúdo - a elevação de linguagem correspondendo ì duração longa do verso - Demétrio (Sobre o Essilo 5) diz que o hexâmetro é chamado de verso heróico por ser adequado a temas heróicos, e que "não seria adequado escrever a llíade de Ilomero nos versos breves de Arquíloco, como a "akifnuméne skulcile"; pois o verso breve serve para temas menores ou passagens vigorosas".

13 Cf. West (1988, p.204-5) e Easterling (1985, p.701). Para Nojgaard (198+, p. 102), as primeiras fábulas cram sempre sérias, isentas do elemento humorístico. 
CORR̂̂A, Paula. A escrita na fábula de Arquíloco (Fr. 185).

\section{B) O ENIGMA DA MENSAGEM}

Voltemos ao fragmento $185 \mathrm{~W}$ e à questão da escrita em Arquíloco. O "eu" inicia o poema afirmando que irá contar um aînos a Kerukídes, que é mais um nome significativo e um patronímico verossímil ${ }^{1+}$, formado de kêruks (k_rux - o "arauto", mensageiro oficial na guerra ou cm relações diplomáticas), c o sufixo -íde (dh): "filho do arauto"1.5.

No segundo verso, a akhnuméne skutále suscitou diversas interpretações e comentários desde o período helenístico. Em primeiro lugar, o que é uma skutále? As dificuldades c controvérsias eram tantas, que Apolônio de Rodes a discutiu em sua obra sobre Arquíloco (_n t_per__Arcil_cou, apud Ath.10.74, 451d); Aristófanes de Bizâncio chegando a escrever um tratado especificamente Sobre a akhnuméne skutále (Per_t_V_cnum_nhV skut_IhV; Ath. Deipn. 3.85e).

Na Sexta Ode Olímpica de Píndaro, Eneas, o corifeu, após ser invocado como um "mensageiro fiel" (v.91_ggeloV_rq_V), é chamado de "skutála (mensagem?) das Musas" (v.92 skut_la Mois_n). Escólios explicam a imagem. Entre esses, os dois que citam o verso de Arquíloco pouco esclarecem: dizem apenas que o corifeu é chamado skutála por ser "arauto" (kêruks) ou "mensageiro" (ángelos) das Musas porque arautos são portadores de skutálai, e que a expressão akhnuméne skutále ocorre nos fragmentos de Arquíloco ${ }^{16}$. Segundo Hesíquio (s.v. skut_lh L_akwnik_) e o Etimologicum Magnum, que glosa skutále por pínaks e déltos, "cra costu-

$1+$ llá pelo menos sete nomes significativos nos fragmentos de Arquíloco: Lukímbes, Neobotile, Leófillos, Dolúdes, Sellédes, Errasmonídes, e Kerukídes; os últimos quatro sendo "patronímicos".

15 C. Bonanno, M. C. (1980, p.74-78). Para Pouilloux (1964, p.12), trata-se de um nome nolore "*nja formaçāo lembra os que se cncontram nas mais antigas listas de magistrados".

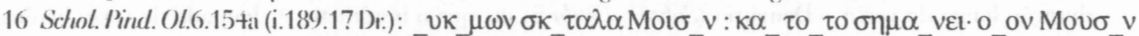

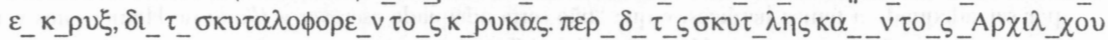

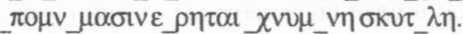

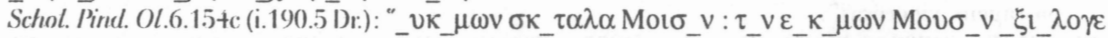

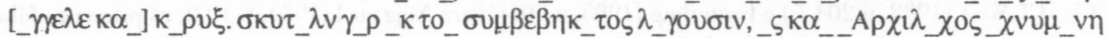
$\sigma \times U \tau \lambda \eta$. 
me dos lacedemônios usarem a skutále (ou o papiro ${ }^{17}$ ) $\mathrm{em}$ vez de tábuas de escrever"18.

Outros escólios ao verso de Píndaro acrescentam dados mais interessantes, informando-nos como era, como funcionava esta skutále lacedemônia. Em três deles (Schol. Pind. Ol.6.154b, d, f), a descrição feita é praticamente a mesma que se encontra no Lisândro (19.4-7) de Plutarco. Diz-se que, para garantir a autenticidade e sigilo de suas mensagens, os antigos lacedemônios deixavam dois bastões de madeira exatamente do mesmo comprimento e espessura ${ }^{19}$, ou cortavam uma vara homogênea pelo meio. Um deles partia com os governadores enviados às colônias, o outro ficava em Esparta. Quando uma das partes precisava enviar notícias, enrolava uma tira de couro ao redor do bastão (chamado skutále), escrevendo nela longitudinalmente. Assim, desenrolada, a faixa contendo o texto escrito era impossível de se ler, a mensagem só podendo ser recuperada por quem tivesse o bastão gêmeo.

Nas outras referências à skutále que ocorrem $\mathrm{cm}$ Aristófanes (Lys. 991ss), Tucídides (1.131.1) e Xenofonte (/lell. 3.3.8), trata-se sempre de um despacho oficial dos lacedemônios, quer seja o bastão (como cm Lisístrata), ou a mensagem. Mas esses não explicam seu emprego ou sua natureza.

Que Plutarco (Lys. 19.4-7) abra um parêntese em sua narrativa para explicar o que era a skutále prova que poucos, em sua época, tinham memória ou conhecimento do que seria exatamente essa skutále lacônica ${ }^{20}$ - cmbora o verso de Arquíloco (akhnuméne skutále), segundo Diogeniano 3.25 (Paroem. Gr. i.217.10) e Apostólio 4.68 (Paroem. Gr. ii.323.8), te-

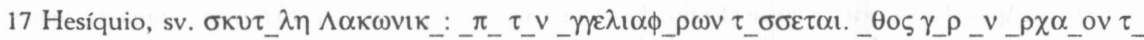

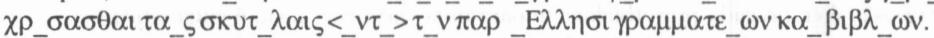

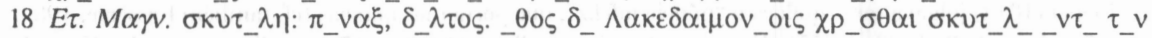
үр $\alpha \mu \mu \alpha \tau \varepsilon_{-} \omega v$.

19 Skutcile era também o nome de uma cobra cujo corpo tinha espessura homogênia (Nic. Th. 384).

$20 \mathrm{~km}$ Plutarco (loc. cit.), porém, a tira que se corola no bastão é um papiro "semelhante a uma tira de couro" ( $\left.\beta 1 \beta \lambda \_o v \_\sigma \pi \varepsilon \rho \_\mu \_v \tau \alpha\right)$. 
nha se trirnado uma expressão proverbial para os "mensageiros de más notícias"21.

Relendo agora os versos de Arquíloco, torna-se evidente a relação entre o aînos (a narrativa com mensagem enigmática/parenética), o destinatário, chamado de "filho do arauto", e a "triste skutále" que, como nota Plutarco (loc. cit.), podia ser tanto o bastão de mensagens cifradas, como as próprias mensagens. O problema é saber se, no poema, a akhnuméne skutále está em aposição ao "filho do arauto", ao "cu" lírico que assim se denomina ou, ainda, se estaria no dativo, associado ao aînos: uma fábula "em triste missiva"

Sem poder decidir qual seria a opção certa, a mais interessante parece ser a segunda: o "eu" lírico apresenta-se como um bastão de mensagens cifradas que irá narrar o aînos, seu relato enigmático, em primeira pessoa aos ouvintes e, especificamente, ao "filho do arauto". A idéia não é bizarra se pensarmos nos primeiros usos da escrita na Crécia antiga, e nos chamados "objetos falantes", comuns no período arcaico, cujas inscrições "falam" com leitor em primeira pessoa.

Um exemplo célebre de "objeto falante" é a "taça de Nestor" (séc. VIII a. C.) que "diz": "Sou a deliciosa taça de Nestor. Aquele que beber dessa taça será tomado pelo desejo da belamente coroada Afrodite". Há várias peças de cerâmica com inscrições desse tipo, "pertenço a...", ou "fulano me fez..."; além das lápides e estátuas que também interpelam os transeuntes. Como diz Thomas (1992, p. 56-65), "A escrita grega arcaica parece estar, portanto, em grande medida a serviço da fala, repetindo versos, fazendo com que objetos possam "falar" como se fossem animados...".

21 Diogen. 3.25 (Paroem. Gr: i.217.10): $\chi v v \mu \_v \eta \sigma \kappa v \tau \_\lambda \eta v . \pi_{-} \tau \_\nu \lambda v \pi \eta \rho \_\varsigma \_\gamma \varepsilon \lambda \_\alpha \varsigma_{-} \gamma \varepsilon \lambda \lambda \_v \tau \omega v .0$ texto em Apostólio (loc. cit.) é quase idêntico. Em Plutarco (sept. sap. conv. 8 p.152e), que é una das fontes do verso, a expressão é empregada proverbialmente para uma carta cujo texto é enigmático.

22 Lichel (1812) julgava ser Arquíloco o "núncio infeliz", que porta más notícias (cf. também Lasserre, 1984, p.74; Camplell, 1983, p.255). Em vista do adjetivo, West (1988, p.+7) acredita que a skiutúle pode referir-se a Kerukides ou a Arquíloco, e opta pelo segundo: "his $\alpha \_$vo̧ does not simply express his own fancy or prejudice, but conveys a message entrusted to him by others". Para Bonanno $(1980, p .78)$ é metonímia em aposição ao "fillho do arauto". 
Quanto à sua função, aqui, como nos outros fragmentos jâmbicos de Arquíloco, o aînos estaria sendo usado como arma contra seus inimigos. Assim, para os que sabem, a sátira contida no aînos da Raposa e do Símio é clara; aos demais, a nós, ela cala - pois não temos o bastão gêmeo para desvendá-la $a^{23}$.

Tal leitura pressupõe os sentidos de aînos discutidos acima, o patronímico satírico e os comentários helenísticos e bizantinos sobre a skutále. Esses últimos foram estudados por Stephanie West (1988) em um artigo que trata especificamente da skutále $\mathrm{cm}$ Arquíloco. Ela conclui que essas fontes não podem ser usadas para uma interpretação dos versos de Arquíloco porque são tardias e, se a escrita foi reintroduzida na Grécia no séc. VIII, seria ainda muito cedo para haver criptografia na época de Arquíloco; a escrita em si já seria decifrada por poucos (West, 1988, p.42). Assim, a skutále de Arquíloco nada teria a ver com a escrita.

Baseando-se em fontes em que a skutále é descrita como o bastão e não a mensagem ${ }^{2+}$, West $(1988$, p.44, 46) diz tratar-se de uma "relíquia da antiga cultura oral": seria um pedaço de madeira que serviria de simbolon ("tally-stick"), conferindo autenticidade ao mensageiro, e que, talvez inscrito com marcas pictóricas, o ajudaria recordar sua mensagem. Mas a autora não leva em conta o verso de Píndaro, nem os escólios $\mathrm{e}$ fontes que indicam a possível transferência de sentidos da skutále que pode referir-se ao bastão, à mensagem, ou ao próprio mensageiro que os levava. Outras evidências a que recorre são externas: uma passagem de Isócrates (12 Panath. 209), segundo o qual os espartanos davam pouco valor à escrita; e a reputação que tinham de ser conservadores, o que teria atrasado o avanço da escrita na Lacônia. A esses testemunhos do analfabetismo espartano, poderíamos somar os comentários nos Dissoi Lógoi (90 F 2.10 DK) e em Platão (Protágoras 342a).

23 Hesíodo (Erga 202ss) conta um aînos para reis, mas só para os que "entendem" ( $\left.\phi \rho o v \_o v \sigma ı v\right)$.

$2+$ Cf. Diose. Hist.+ (para o "tally-stick"); parte do escólio Ol. 6.15+.f; e Hesíquio (s.v.), onde parece que escreviam na própria skutále. 
CORRÊA, Paula. A escrita na fábula de Arquíloco (Fri. / S5).

No entanto, é importante lembrar que essas imputações feitas no quinto século por atenienses contra espartanos estão, no mínimo, carregadas de chauvinismo ${ }^{25}$. Além disso, no período arcaico, o ambiente cultural em Esparta era bem diverso, florescendo com poetas e músicos, locais e estrangeiros (Álcman, Terpândro e Tirteu). Se os espartanos não publicavam leis e documentos, por outro lado, sua diplomacia era a mais desenvolvida em toda Grécia (Cartledge, 1978, p.30). Em Heródoto (7.239), a estória da mensagem enviada por Demarato é exemplo do engenho espartano quando se tratava de despachos secretos entre comandantes ${ }^{26}$.

Portanto, se aceitarmos a hipótese de Jeffery (1961, p.57-8) de que a escrita foi introduzida em Esparta no séc. VIII, c que o suporte material mais comum na época era o couro ${ }^{27}$, não seria impossível que, um século mais tarde, para fins diplomáticos e estratégicos, enviassem mensagens em skutálai. Que a skutále no período arcaico fosse apenas um sistema cm que a mensagem era escrita sobre o couro e depois enrolada no bastão para simples transporte, (como sugere Jeffery, loc. cit.), e não a técnica de cifrar transmitida pelas fontes helenísticas, é também possível. Isto depende do grau de sofisticação que se queira conceder aos espartanos do séc. VII a. C.

Sugerimos, portanto, que nesse dístico o "cu lírico", chamando-se de skutále, uma mensagem escrita, conta em primeira pessoa, ao "filho do arauto" que o lê, uma triste fábula. Essa interpretação, porém, assim como as outras, não resolve o enigma. E a estória permanece cifrada, se não por estar na skutále, certamente por ser aînos.

25 Nlén da skutále, I larvey (1966, p.625) arrola evidências de que os espartanos cram letrados: 1. cartas enviadas por comandantes (Th. 8.33.3), 2. o registro de respostas délficas (1 Idt. 6.57.4), 3. livros (Estrabão 8.5.5), e t. tratados escritos e exibidos publicamente (Th. 5.77.79; 5.18.10).

26 Demarato teria raspado a cera da tábua de escrever, inscrito a mensagem secreta na própria madeira e recoberto a tálsua, levando o portador a crer que não levava mensagem alguma.

27 Os Pylhioi terian trazido de Delfos oráculos inscritos em tiras de couro (cf. Eur: fr:627 Nauck). 
Revista da ANPOLL, n" 4, p. 249-261, jan./jun. 1998

ABSTRACT: Since antiquity, the "skiutale" in Archilochus (Fr: 185W) has led to different interpretations. It has been considered as a "written message" (encoded or not), as a message-stick (which somehow bore the message or only served as the messager's credentials), or as the messager himself. In order to read these verses which introduce the "Fable of the Fox and the Monkey" (Fr. 185-7), and to specify. the meaning of the word in this context, the uses of "ainos" (greek "fabula"), the fragment's sources, ancient evidence of the "skutále" and other forms of dispatches are analized.

KEYWORDS: literacy, fable, ancient greck liric.

\section{BIBLIOGRAFIA}

Edições de Arquíloco

BERGK, T. Poelae Lyrici Craeci. vol II. Leipzig: $1882(1915)^{+}$.

CAMPBELL, D. A. Greek Lyric Poetry: A Selection of Early Greek Lyric, Elegiac and lambic Poetry. Bristol: 1982.

DIEHI, E. (ed.) Anthologia Lyrica Craeca. Leipzig: 1926', 1936², $1952^{3}$.

EDMONDS, J. M. Greek Elegy and lambus. London: 1931.

IILLER, E. Anthologia Lyrica Graeca sive Lyricorum Graecorum Veterum praeter Pindarum. Leipzig: 1890.

HOFFMANN, O. Die Griechischen Dialekte In Ihrem Ilistorischen Zusammenhange (vol 3): Der Ionische Dialekl. Göttingen: 1898.

LASSERRE, F. Les Épodes d'Archiloque. Paris: 1950.

IASSERRE, F e BONNARD, A. Archiloque: Fragments. Paris: 1968.

LIEBEL, I. Archilochi Reliquiae. I seiprig: 1812.

SCHNEIDEWIN, F. G. Delectus Poesis Graecorum Elegiacae, Iambicae, Melicae. Göttingen: 1838.

TARDITI, G. Archiloco. Roma: 1968.

TREU, M. Archilochos. München: 1959. 


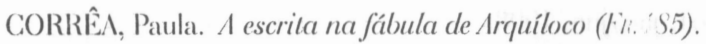

WEST, M. L. Iambi et Elegi Graeci ante Alexandrum Cantali I. Oxford: 1971', 1989².

BARRON, J. P. \& EASTERIINC, P. E. "Archilochus" $\mathrm{em}$ The Cambridge History" of Classical Lileralure I. Greek Lileralure. Ed. P. E. Easterling e B. M. W. Knox. Cambridge: 1985.

BONANNO, M. C. "Nomi e soprannomi archilochei". MH 37 (1980) 65-88.P.

CAMPBELL, D. A. The Golden Lyre; the Themes of the Greek Lyric Poets. London: 1983.

CARTILEDCE, P. "Iiteracy in the Spartan Oligarchy" JIIS 68 (1978) 25-37.

EASTERLINC, P. E. "Fable" em The Cambridge I History of Classical Literature I. Greek Lileralure. Ed. P. E. Easterling e B. M. W. Knox. Cambridge: 1985.

CENTILI, B. Poetry and its Public in Ancient Greece from Homer to the Fifth Century. Trad. A. T. Cole. Baltimore \& London: 1988.

I IARVEY, F. D. "Literacy in the Athenian Democracy" REG 79 (1966) 585-635.

IIAUVETTE, A. Archiloque, sa vie et ses poésies. Paris: 1905.

JEFFERY, L. II. The Local Scripls of Archaic Greece. Oxford: 1961.

IASSERRE, F. "La fable en Crèce dans la poésie auchäque" in La Fable, Entreliens sur l'Antiquilé Classique XXX, pp.61-104, Vandoevres-Genève: 1984.

LURIA, S. "Der Affe des Archilochos und die Brautwerbung des Ilippok leides" Philologus 85 (1930) 1-22.

NOJGANRD, M. "I a moralisation de la fable: d'Ésope à Romulus" in La Fabte, Entreliens sur l'Antiquilé Classique XXX, pp. 225-252, Vandoevres-Cenève: 1984.

PACE, D. L. "Archilochus and the Oral Tradition." em Archiloque, Entretiens sur l'antiquilé classique X. Genève: 1964, p.117-64.

PERRY, B. E. Babrius and Phaedrus. London: 1965.

POUILloUX, J. "Archiloque et Thasos: Histoire et Poésie" em Archiloque, Entreliens sur l'anliquité classique X. Genève: 1964, p.117-64.

RICHIARDSON, N. The Iliad: A Commentary: Vol. VI: books 21-24. Editor geral: C. S. Kirk. Cambridge: 1993. 
Revista da ANPOLL, n 4, p. 249-261, jan./jun. 1998

THOMAS, R. Lileracy and Orality in Ancient Greece. Cambridge: 1992.

VERDENIUS, W. J. "AINOS”. Mnemosyne 4, vol.15 (1962) 389.

WEST, M. L. "The Ascription of Fables to Aesop in Archaic and Classical Greece", in La Fable, Entretiens sur l'Antiquité Classique XXX, pp.105-136, Vandoevres-Cenève: 1984.

WEST, S. "Archilochus' Message-stick" C() 38 (1988) 42-48. 